\section{(d) \\ CrossMark}

\title{
The European Respiratory Review: continuing the success and targeting new challenges
}

\author{
Yochai Adir
}

Affiliation: Pulmonary Division, Lady Davis Carmel Medical Center, Faculty of Medicine, The Technion, Institute of Technology, Haifa, Israel.

Correspondence: Yochai Adir, Pulmonary Division, Lady Davis Carmel Medical Center, 7 Michal Street, Haifa, 3436212, Israel. E-mail: adir-sh@zahav.net.il

@ERSpublications

Continuing the success of the European Respiratory Review: the new Chief Editor identifies new challenges http://ow.ly/oSi730nmrPj

Cite this article as: Adir Y. The European Respiratory Review: continuing the success and targeting new challenges. Eur Respir Rev 2019; 28: 190001 [https://doi.org/10.1183/16000617.0001-2019].

The European Respiratory Review (ERR) is now over 20 years old, and during those years it has become a source of current and relevant information in our discipline. The overall number of visits to the ERR website and the number of downloaded review articles is constantly increasing, not only in Europe but all over the world, with more than 800000 visits and 2.75 million HTML/PDF downloads in 2018. The ERR is already included in many international indexes and databases, and an important landmark was achieved in November 2018 when the ERR was accepted for indexing by Clarivate Analytics in the Science Citation Index Expanded (SCIE), meaning that it will receive its first Impact Factor in the summer of 2019. Articles from 2016 onwards will now be included in the SCIE, as well as the Journal Citation Reports and Current Contents.

This is a remarkable achievement, which has become a reality thanks to the amazing stewardship of my predecessors, Marc Humbert, Vincent Cottin and Sergio Harari, together with the support of the editorial board members and the outstanding assistance of the Publications Office staff (Sheffield, UK). Becoming the Chief Editor is a humbling honour and it will be a challenge to maintain the ERR's high standards and further improve the visibility and impact of the ERR.

A first step will encompass restructuring the editorial board. We plan to have a strong international representation, not only from Europe but also from Asia, the USA, South America and Africa. Furthermore, the ERR will be strengthened by having a diverse editorial board, including younger scientists and groups that have historically been underrepresented. We will create a new role in the editorial board, to be known as "section editor". There will be several section editors, including respiratory physicians with specialties in specific areas of pulmonary medicine, such as interstitial lung diseases, obstructive lung diseases, lung cancer, critical care, interventional bronchoscopy, pleural diseases, pathology, sleep disorders, translational medicine, cystic fibrosis, lung infections, lung transplantation and pulmonary vascular disease, as well as a section editor with a focus on social media. Social media will be given close attention, with special emphasis on Twitter (@ERSPublications), aiming to increase current and readership-responsive activities by using social media to exchange ideas and highlight new publications.

Provenance: Submitted article, peer reviewed.

Received: Jan 082019 | Accepted: Jan 092019

Copyright OERS 2019. ERR articles are open access and distributed under the terms of the Creative Commons Attribution Non-Commercial Licence 4.0. 
In an era when there are numerous medical publications and an increasing number of respiratory journals, the general pulmonary practitioner needs, more than ever, access to the latest information about specific diseases, treatments and new technical procedures via current and relevant concise reviews. We should strive for the ERR to be the first choice for an excellent source of knowledge when a pulmonary specialist or non-specialist is in need of updated information in our field. We need to publish practical reviews on topics relevant to the pulmonary specialist in daily practice and also to provide information on the molecular mechanisms and precision medicine.

We should continue to focus on the global visibility of the ERR and to increase our relevance not only in Europe but all over the world.

Finally, we will have our first Impact Factor ranking this summer. To keep and further improve the Impact Factor, future efforts will be needed to maintain and increase the quality of the published manuscripts in the $E R R$, in order to increase the number of citations in international journals.

Ultimately, to continue building upon the success of the $E R R$, we need your support through reading the articles and providing us with feedback via social media and by submitting proposals. Only if we continue to work together will we continue the success of the ERR, leading it to new heights by increasing our knowledge and improving the care of our patients.

Conflict of interest: Y. Adir has nothing to disclose. 